\title{
Uncatalysed Production of Coumarin-3-carboxylic Acids: A Green Approach
}

\author{
Joel Martínez, ${ }^{1,2}$ Lilibeth Sánchez, ${ }^{1}$ F. Javier Pérez, ${ }^{3}$ Vladimir Carranza, ${ }^{4}$ \\ Francisco Delgado, ${ }^{5}$ Leonor Reyes, ${ }^{5}$ and René Miranda ${ }^{1}$ \\ ${ }^{1}$ Departamento de Ciencias Químicas, Facultad de Estudios Superiores Cuautitlán, Universidad Nacional Autónoma de México, \\ 54740 Cuautitlán Izcalli, MEX, Mexico \\ ${ }^{2}$ Facultad de Ciencias Químicas, Posgrado en Ciencias en Ingeniería Química, Universidad Autónoma de San Luis Potosí, \\ 78210 San Luis Potosí, SLP, Mexico \\ ${ }^{3}$ Instituto de Química, Universidad Nacional Autónoma de México, Ciudad Universitaria, 04510 Ciudad de México, Mexico \\ ${ }^{4}$ Laboratorio de Espectrometría de Masas, Centro de Química ICUAP, Benemérita Universidad Autónoma de Puebla, \\ 72570 Puebla, PUE, Mexico \\ ${ }^{5}$ Escuela Nacional de Ciencias Biológicas, Instituto Politécnico Nacional, Casco de Santo Tomas, 11340 Ciudad de México, Mexico
}

Correspondence should be addressed to Joel Martínez; atlanta126@gmail.com

Received 10 June 2016; Accepted 1 August 2016

Academic Editor: Artur M. S. Silva

Copyright (C) 2016 Joel Martínez et al. This is an open access article distributed under the Creative Commons Attribution License, which permits unrestricted use, distribution, and reproduction in any medium, provided the original work is properly cited.

\begin{abstract}
A green contribution in short reaction times with moderate yields to produce coumarin-3-carboxylic acids is offered. Five different modes to activate the reactions (microwave, near-infrared, mechanical milling, and ultrasound) were compared with mantle heating in the presence or absence of ethanol, a green solvent. Near-infrared and microwave irradiations deliver the best yields in contrast to ultrasound and mechanical milling; moreover, these four processes offered shorter reaction times in comparison with the conventional mantle heating method. It is also important to highlight that the obtained molecules were produced without the requirement of a catalyst and two nonconventional energies forms are presented as new processes.
\end{abstract}

\section{Introduction}

Coumarins, benzo-2-pyrone derivatives, are an important class of compounds in the field of natural products because they display a broad array of biological activities [1], in particular as antioxidants [2], anti-HIV agents [3], anticancer agents [4], and vasorelaxants $[5,6]$. They have also been used in the pharmaceutical, perfumery, and agrochemical industries as starting materials or intermediates. Consequently, this class of molecules has been incorporated in the preparation of numerous organic compounds [7]. Various protocols have been used for their synthesis, including the Pechmann [8], Perkin [9], Knoevenagel [10], Reformatsky [11], Wittig [12], and Claisen reactions [13].

On the other hand 2,2-dimethyl-1,3-dioxane-4,6-dione (Meldrum's acid) has attracted considerable attention due to its high acidity and rigid cyclic structure [14]. This versatile molecule is an important substrate for many interesting organic transformations such as the preparation of pyridones [15], pyrimidines, and azoloazines in tandem reactions [16] and the synthesis of natural products [17] and, of particular interest for this work, as a condensation partner to generate coumarins [18-21].

Owing to the value of these molecules, a search for new and more convenient methods of preparation is desirable, mainly if the novel offered procedure diminished pollution; in other words, with proper green approach, the adoption of novel cleaner methods must be an urgent priority. Some efforts, with occurrence in the Green Chemistry Protocol, have been explored to prepare coumarins derivatives, many of them using green approaches, for example, zeolites [23], clays [22], cation exchange resins [24], solventless [25] and solidphase [26] conditions, reflux in water [18], microwave irradiation [19], oxidative cyclocarbonylation [27], using mixtures of 
PEG400/ $\mathrm{H}_{2} \mathrm{O}$ or PEG400/EtOH as solvents [28], ultrasound [29], and room temperature [30]. However, many of these procedures involve long time reactions and the presence of a solvent or catalyst or both.

As a part of our ongoing research program, we are very interested in the development of green procedures for the production of different heterocycles with interesting pharmacological properties. Consequently, the goal of the present work was to create a green approach [31] for the production of several coumarins using Meldrum's acid as a reagent, offering an insightful study by comparison of five different modes to activate the reaction: microwave (MW) and near-infrared (NIR) irradiations, ultrasound (US), and mechanical milling (MM) versus the typical mantle heating $(\mathrm{MH})$. Some of experiments were carried out in ethanol, a green solvent, according to the TRI-EPA [32]. It is also worth noting that a careful search of the literature revealed that this is the first report wherein near-infrared irradiation [33] and mechanical milling or tribochemistry [34] have been employed to carry out reaction successfully. In general, in this work an acute procedure for the green synthesis of various coumarin-3-carboxylic acids in moderate yields and in short reaction times is provided.

\section{Materials and Methods}

General. Starting materials salicylaldehyde (1a), 2-hydroxy-5methylbenzaldehyde (1b), 2-hydroxy-3-methylbenzaldehyde (1c), 2-hydroxy-4-methoxybenzaldehyde (1d), 2-hydroxy-1naphthaldehyde (1e), and solvents were purchased from Sigma Aldrich Chemical and used without further purification. Meldrum's acid was prepared according to a literature procedure [35]. ${ }^{1} \mathrm{H}$ and ${ }^{13} \mathrm{C}$ NMR (DMSO- $d_{6}$ ) spectra were recorded using a Varian Mercury-300 spectrometer at $300 \mathrm{MHz}$ and $75 \mathrm{MHz}$ for hydrogen and carbon, respectively. The multiplicities are reported as singlet (s), doublet (d), triplet $(\mathrm{t})$, doublet of doublet (dd), and triplet doublet (td). The EIMS $(70 \mathrm{eV})$ were determined using a JEOL JMS700 MStation mass spectrometer. The HRMS-DART ${ }^{+}$data were obtained using a JEOL AccuTOF (Direct Analysis in Real Time) mass spectrometer. The measurements were performed using a DART experiment with PEG (polyethylene glycol) 400 as internal reference at 6000 resolutions and triplet helium as carrier gas at $350^{\circ} \mathrm{C}$. In the first orifice, the temperature and voltage were $120^{\circ} \mathrm{C}$ and $15 \mathrm{~V}$, respectively, and the voltage in the second orifice was $5 \mathrm{~V}$. Elemental composition was calculated within a mass range of $\pm 10 \mathrm{ppm}$ from the measured mass. Melting points were determined using a Fisher-Johns apparatus and are uncorrected. Microwave-assisted synthesis of the target compounds was performed using a CEM Focused Microwave ${ }^{\mathrm{TM}}$ Synthesis System. Near-infrared irradiation was generated using a commercial "Flavor-Wave ${ }^{\circledR ”}(1300 \mathrm{~W} / 110 \mathrm{~V} / 120 \mathrm{~V}$ $60 \mathrm{~Hz} \mid 220 \mathrm{~V} / 240 \mathrm{~V}-60 \mathrm{~Hz}$ ) device [33]. Ultrasound-assisted synthesis was performed using a Transonic 460/H Elma ultrasound bath $(35 \mathrm{kHz})$. Mechanical milling was conducted using a Ball Mill PM 100 Retch, using25 carbon steel balls (weight $11,050 \mathrm{mg}, 3 / 16^{\prime \prime}$ diameter). It was not possible to determine temperature and pressure in this device. In the NIR and ultrasound experiments, the temperature was measured using an infrared thermometer (Infrared + Type K Thermometer, Extech Instruments, Sigma Aldrich 2509388-1 EA) with the laser pointer directed to the center of reaction. The progress of the reactions was monitored by TLC using silica gel $60-\mathrm{F}_{254}$ coated aluminum sheets ( $n$-hexane-ethyl acetate $6: 4$ ) visualized using a UV light at $254 \mathrm{~nm}$.

2.1. Method A (with Solvent). A mixture of aldehyde 1a (120 mg, $0.9833 \mathrm{mmol}), 1 b$ (140 mg, $1.0290 \mathrm{mmol}), 1 c(140 \mathrm{mg}$, $1.0290 \mathrm{mmol}), \mathbf{1 d}(140 \mathrm{mg}, 0.9865 \mathrm{mmol})$ or 1 e $(140 \mathrm{mg}$, $0.9881 \mathrm{mmol})$, Meldrum's acid 2 (150 mg, $1.0408 \mathrm{mmol})$, and EtOH $(5 \mathrm{~mL}$ for US and NIR, $2 \mathrm{~mL}$ for $\mathrm{MW}$ and $0.5 \mathrm{~mL}$ for MM) was placed in an appropriate Erlenmeyer flask, bottom flask, or steel container. The mixtures were treated using different activation modes: near-infrared irradiation for $20 \mathrm{~min}$ at $70^{\circ} \mathrm{C}$ with vigorous magnetic stirring, placing the magnetic agitator under Flavor-Wave, microwave irradiation for $1 \mathrm{~min}$ at $70^{\circ} \mathrm{C}$ (run time), and then $5 \mathrm{~min}$ at $70^{\circ} \mathrm{C}$ (hold time) with medium level stirring and $100 \mathrm{~W}$ power; ultrasound bath for $30 \mathrm{~min}$ at $70^{\circ} \mathrm{C}$; mechanical milling for $25 \mathrm{~min}$ with $400 \mathrm{rpm}$ and $27 \%$ power. All reactions were conducted in open vessels and monitored by TLC (silica gel, $n$-hexaneethyl acetate $6: 4$ ). After cooling, ice-water was added to the flask to precipitate the product, and the solid collected to give the corresponding pure coumarin-3-carboxylic acid.

2.2. Method B (Solventless). A mixture of aldehyde 1a (120 mg, $0.9833 \mathrm{mmol}), \mathbf{l b}(140 \mathrm{mg}, 1.0290 \mathrm{mmol}), \mathbf{1 c}(140 \mathrm{mg}$, $1.0290 \mathrm{mmol}), \mathbf{1 d}(140 \mathrm{mg}, 0.9865 \mathrm{mmol})$ or 1 e $(140 \mathrm{mg}$, $0.9881 \mathrm{mmol})$, and Meldrum's acid $2(150 \mathrm{mg}, 1.0408 \mathrm{mmol})$ was placed in an appropriate Erlenmeyer flask, bottom flask, or steel container. The mixtures were treated using different activation modes: near-infrared irradiation for $25 \mathrm{~min}$ at $80^{\circ} \mathrm{C}$; microwave irradiation for $1 \mathrm{~min}$ at $80^{\circ} \mathrm{C}$ (run time) and then $10 \mathrm{~min}$ at $80^{\circ} \mathrm{C}$ (hold time); ultrasound bath for $60 \mathrm{~min}$ at $65^{\circ} \mathrm{C}$; mechanical milling for $40 \mathrm{~min}$ with $400 \mathrm{rpm}$ and $27 \%$ power; mantle heating for $90 \mathrm{~min}$ at $90^{\circ} \mathrm{C}$. All reactions were conducted in open vessels and monitored by TLC (silica gel, $n$-hexane-ethyl acetate $6: 4$ ). After cooling, ice-water was added to the flask to extract the product, and the solid collected to give the corresponding pure coumarin3-carboxylic acid.

2-Oxo-2H-chromene-3-carboxylic Acid (3a). White powder, mp 190-191 ${ }^{\circ} \mathrm{C} ;{ }^{1} \mathrm{H}$ NMR (300 MHz; DMSO- $\left.d_{6}\right)(\delta / \mathrm{ppm}): 8.71$ (s, $1 \mathrm{H}, \mathrm{H} 4), 7.87(\mathrm{dd}, J=7.65 \mathrm{~Hz}, 1 \mathrm{H}, \mathrm{H} 5), 7.69(\mathrm{td}, J=7.87 \mathrm{~Hz}$, $1 \mathrm{H}, \mathrm{H} 7), 7.40$ (t, $J=6.3 \mathrm{~Hz}, 1 \mathrm{H}, \mathrm{H6}$ ), 7.35 (d, $J=7.65 \mathrm{~Hz}$, $1 \mathrm{H}, \mathrm{H} 8$ ); the proton of $\mathrm{COH}_{2}$ was not observable, probably because the concentration of nuclei which produce the signal was poor or because of fast dissociation [36]; in addition, the exchange with the deuterated solvent or water from solvent itself can occur; ${ }^{13} \mathrm{C}$ NMR $\left(75 \mathrm{MHz}\right.$; DMSO- $\left.d_{6}\right)(\delta / \mathrm{ppm})$ : $164.0\left(\mathrm{CO}_{2} \mathrm{H}\right), 156.7(\mathrm{C} 2), 154.5(\mathrm{C} 8 \mathrm{a}), 148.4(\mathrm{C} 4), 134.3$ (C7), 130.2 (C5), 124.8 (C8), 118.4 (C3), 118.0 (C6), 116.2 (C4a); 

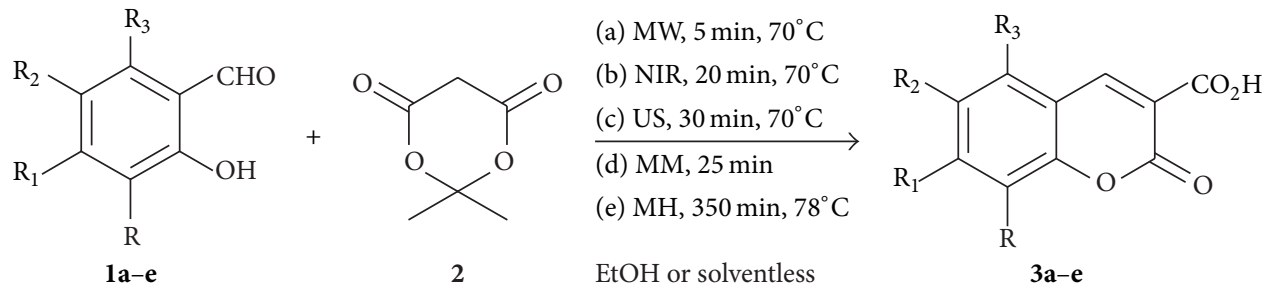

SCHEME 1: Production of coumarins. Reagent or Product: $\mathbf{a} R=\mathrm{R}_{1}=\mathrm{R}_{2}=\mathrm{R}_{3}=\mathrm{H} ; \mathbf{b} \mathrm{R}=\mathrm{R}_{1}=\mathrm{H}, \mathrm{R}_{2}=\mathrm{Me}, \mathrm{R}_{3}=\mathrm{H} ; \mathbf{c} \mathrm{R}=\mathrm{Me}, \mathrm{R}_{1}=\mathrm{R}_{2}=\mathrm{R}_{3}=$ $\mathrm{H} ; \mathbf{d} \mathrm{R}=\mathrm{H}, \mathrm{R}_{1}=\mathrm{OMe}, \mathrm{R}_{2}=\mathrm{R}_{3}=\mathrm{H} ; \mathbf{e} \mathrm{R}=\mathrm{R}_{1}=\mathrm{H}, \mathrm{R}_{2}-\mathrm{R}_{3}=\mathrm{CHCH}=\mathrm{CHCH}$.

EIMS $(70 \mathrm{eV}) \mathrm{m} / z(\%): 190(47) \mathrm{M}^{+\bullet}, 173(13)[\mathrm{M}-17]^{+}, 146$ (100) $[\mathrm{M}-44]^{+\bullet}, 118(61)[\mathrm{M}-72]^{+\bullet}$.

6-Methyl-2-oxo-2H-chromene-3-carboxylic Acid (3b). White powder, mp $158-159^{\circ} \mathrm{C} ;{ }^{1} \mathrm{H}$ NMR $\left(300 \mathrm{MHz}\right.$; DMSO- $\left.d_{6}\right)$ $(\delta / \mathrm{ppm}): 8.62(\mathrm{~s}, 1 \mathrm{H}, \mathrm{H} 4), 7.64(\mathrm{~s}, 1 \mathrm{H}, \mathrm{H} 5), 7.52(\mathrm{~d}, J=8.4 \mathrm{~Hz}$, $1 \mathrm{H}, \mathrm{H} 8), 7.31$ (dd, $J=8.4 \mathrm{~Hz}, 1 \mathrm{H}, \mathrm{H} 7), 2.35$ (s, 3H, H9); the proton of $\mathrm{COH}_{2}$ was not observable, probably because the concentration of nuclei which produce the signal was poor or because of fast dissociation [36]; in addition, the exchange with the deuterated solvent or water from solvent itself can occur; ${ }^{13} \mathrm{C}$ NMR $\left(75 \mathrm{MHz}\right.$; DMSO- $\left.d_{6}\right)(\delta / \mathrm{ppm})$ : 164.1 ( $\left.\mathrm{CO}_{2} \mathrm{H}\right), 157.0(\mathrm{C} 2), 152.6(\mathrm{C} 8 \mathrm{a}), 148.1(\mathrm{C} 4), 135.2(\mathrm{C} 7)$, 134.2 (C6), 129.6 (C5), 118.4 (C3), 117.7 (C4a), 115.9 (C8), 20.2 (C9); EIMS (70 eV) m/z (\%): $204(12) \mathrm{M}^{+\bullet}, 205(100)[\mathrm{M}+$ $\mathrm{H}]^{+}, 187(85)[\mathrm{M}-17]^{+}, 160(9)[\mathrm{M}-44]^{+\bullet}, 103(5)[\mathrm{M}-101]^{+}$.

8-Methyl-2-oxo-2H-chromene-3-carboxylic Acid (3c). White needless, mp $155-156^{\circ} \mathrm{C} ;{ }^{1} \mathrm{H}$ NMR $\left(300 \mathrm{MHz}\right.$; DMSO- $d_{6}$ )

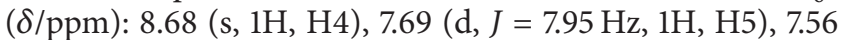
(d, $J=7.05 \mathrm{~Hz}, 1 \mathrm{H}, \mathrm{H} 7), 7.26$ (t, $J=7.65 \mathrm{~Hz}, 1 \mathrm{H}, \mathrm{H6}$ ), 2.34 (s, $3 \mathrm{H}, \mathrm{H} 9$ ); the proton of $\mathrm{COH}_{2}$ was not observable, probably because the concentration of nuclei which produce the signal was poor or because of fast dissociation [36]; in addition, the exchange with the deuterated solvent or water from solvent itself can occur; ${ }^{13} \mathrm{C}$ NMR $\left(75 \mathrm{MHz}, \mathrm{DMSO}-d_{6}\right)(\delta / \mathrm{ppm})$ : 164.1 $\left(\mathrm{CO}_{2} \mathrm{H}\right), 156.8(\mathrm{C} 2), 152.8$ (C8a), 148.7 (C4), $135.3(\mathrm{C} 7)$, 127.9 (C5), 125.1 (C8), 124.4 (C6), 117.9 (C3), 117.7 (C4a), 14.9 (C9); EIMS $(70 \mathrm{eV}) \mathrm{m} / z(\%): 204(18) \mathrm{M}^{+\bullet}, 187$ (2) [M $17]^{+}, 160(100)[\mathrm{M}-44]^{+\bullet}, 132(78)[\mathrm{M}-72]^{+\bullet}, 103(29)[\mathrm{M}$ - 101] ${ }^{+}$; HRMS-DART ${ }^{+}$for $\mathrm{C}_{11} \mathrm{H}_{9} \mathrm{O}_{4}[\mathrm{M}+\mathrm{H}]^{+}$, calculated 205.0501 Da, experimental 205.0509 Da.

7-Methoxy-2-oxo-2H-chromene-3-carboxylic Acid (3d). White powder, mp 187-188 ${ }^{\circ} \mathrm{C} ;{ }^{1} \mathrm{H}$ NMR $\left(300 \mathrm{MHz}\right.$; DMSO- $d_{6}$ ) ( $\delta / \mathrm{ppm}): 8.71(\mathrm{~s}, 1 \mathrm{H}, \mathrm{H} 4), 7.82(\mathrm{~d}, J=9.0 \mathrm{~Hz}, 1 \mathrm{H}, \mathrm{H} 5), 7.02$ (d, $J=8.1 \mathrm{~Hz}, 1 \mathrm{H}, \mathrm{H} 6), 6.98$ (s, $1 \mathrm{H}, \mathrm{H} 8), 3.86$ (s, 3H, H9); the proton of $\mathrm{COH}_{2}$ was not observable, probably because the concentration of nuclei which produce the signal was poor or because of fast dissociation [36]; in addition, the exchange with the deuterated solvent or water from solvent itself can occur; ${ }^{13} \mathrm{C}$ NMR (75 MHz; DMSO- $\left.d_{6}\right)(\delta / \mathrm{ppm}): 164.7$ (C7), 164.2 ( $\left.\mathrm{CO}_{2} \mathrm{H}\right), 157.2(\mathrm{C} 2), 156.9(\mathrm{C} 8 \mathrm{a}), 149.1(\mathrm{C} 4), 131.6(\mathrm{C} 5)$, 113.9 (C3), 113.3 (C6), 111.6 (C4a), 100.3 (C8), 56.3 (C9); EIMS $(70 \mathrm{eV}) \mathrm{m} / z(\%): 220(100) \mathrm{M}^{+\bullet}, 203(16)[\mathrm{M}-17]^{+}, 192(14)$ $[\mathrm{M}-28]^{+\bullet}, 176(77)[\mathrm{M}-44]^{+\bullet}, 148(43)[\mathrm{M}-72]^{+\bullet}, 133(50)$ $[\mathrm{M}-87]^{+}$.
3-Oxo-3H-benzo[f]chromene-2-carboxylic Acid (3e). Yellow powder, mp $239-241^{\circ} \mathrm{C} ;{ }^{1} \mathrm{H}$ NMR $\left(300 \mathrm{MHz}\right.$; DMSO- $d_{6}$ )

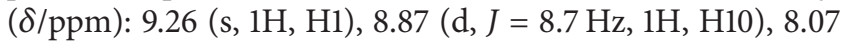
$(\mathrm{d}, J=9.0 \mathrm{~Hz}, 1 \mathrm{H}, \mathrm{H} 6), 7.84(\mathrm{~d}, J=7.8 \mathrm{~Hz}, 1 \mathrm{H}, \mathrm{H} 5), 7.58(\mathrm{t}$, $J=7.65 \mathrm{~Hz}, 1 \mathrm{H}, \mathrm{H} 9), 7.39$ (t, $J=7.8 \mathrm{~Hz}, 1 \mathrm{H}, \mathrm{H} 8), 7.20$ (d, $J$ $=9.3 \mathrm{~Hz}, 1 \mathrm{H}, \mathrm{H} 7)$; the proton of $\mathrm{COH}_{2}$ was not observable, probably because the concentration of nuclei which produce the signal was poor or because of fast dissociation [36]; in addition, the exchange with the deuterated solvent or water from solvent itself can occur; ${ }^{13} \mathrm{C}$ NMR $\left(75 \mathrm{MHz}\right.$; DMSO- $\left.d_{6}\right)$

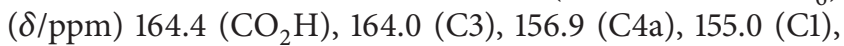
135.8 (C6), 131.7 (C10a), 129.3 (C6a), 127.6 (C10), 126.4 (C9), 122.2 (C7), 122.1 (C8), 117.2 (C2), 112.4 (C5), 112.1 (Cla); EIMS $(70 \mathrm{eV}) \mathrm{m} / z(\%): 240(10) \mathrm{M}^{+\bullet}, 223(2)[\mathrm{M}-17]^{+}, 194(100)[\mathrm{M}$ $-46]^{+\bullet}, 168(11)[\mathrm{M}-72]^{+\bullet}$.

\section{Results and Discussion}

3.1. Synthesis. In order to minimize the energy requirements of a given process, various attempts were made to make the energy input as efficient as possible for the production of the 3 -carboxycoumarins (3a-e). Five salicylaldehydes $(\mathbf{1 a}-\mathbf{e})$ were treated with Meldrum's acid (2) under four nonconventional activating methods (MW, NIR, US, and MM) and with mantle heating $(\mathrm{MH})$ under solventless conditions or in ethanol without a catalyst (Scheme 1). In general, these onepot processes occur via a typical Knoevenagel condensation according to the literature [17]. The results are summarized in Table 1.

The performance of US-assistance may be due to ultrasonic acceleration effects on the liquid system, explained by cavitation-collapse promoting low-energy chemical reactions [29]. With regard to the low yields for MM, it is known that various tribophysical phenomena exist [37]: it is possible that the formation of electrons and positive ions to produce the required plasma was not generated in an appropriate quantity, reducing the production of triboplasma, leading to poor lubrication of the tribosystem and consequently affording low yields. The yields obtained with NIR and MW were similar due to the fact that both must be directly absorbed by the solvent and the reagents, resulting in a rapid temperature rise in the system and consequently increasing reactivity [38].

All of these methods fit appropriately with the sixth principle of the Green Chemistry Protocol, that is, decreasing energy consumption. The solvent, ethanol, has a high $\tan \delta$ 
TABLE 1: Formation of coumarins using five activating modes.

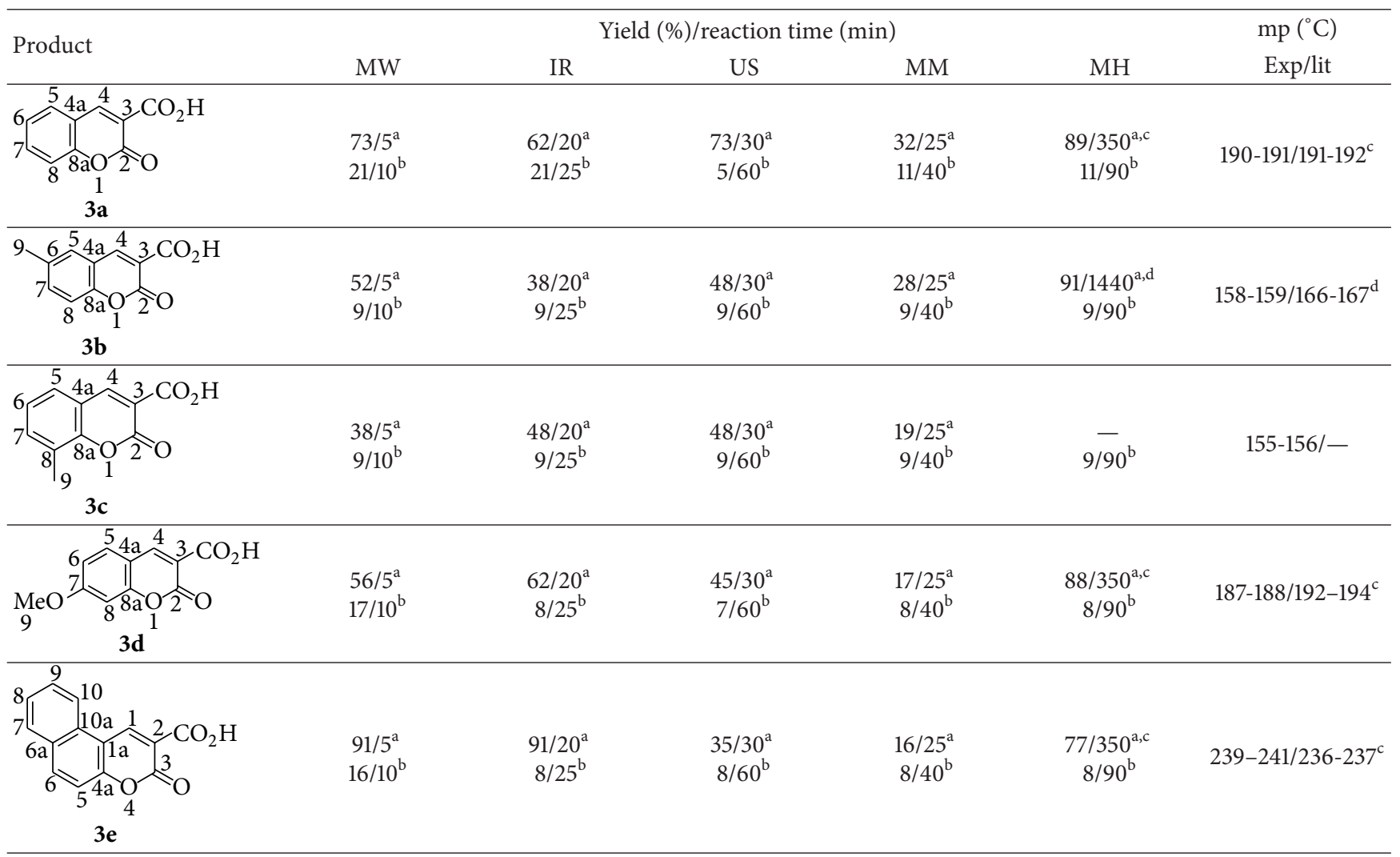

MW: microwave irradiation; NIR: near-infrared irradiation; US: ultrasound; MM: mechanical milling; MH: mantle heating; Exp: experimental; Lit: literature; ${ }^{a}$ in EtOH; ${ }^{b}$ solventless; ${ }^{c}$ see [21]; ${ }^{d}$ see [22].

value (0.941), a measure of its ability to convert electromagnetic energy into heat [39], also favoring efficient energy absorption. It is also important to take into account that it is a green solvent because of its low toxicity and good degradability $[31,32,40]$ in accordance with the fifth principle of the green protocol; moreover, the use of ethanol instead of pyridine or piperidine as solvent supports the third and twelfth green chemistry principles. The use of sodium azide, lithium bromide, ammonium acetate, potassium carbonate, palladium, and other catalyst, several of which considered as toxic by TRI-EPA, was avoided in agreement with the third and twelfth green chemistry principles. The byproducts generated are water, green molecule, and ketone, all classified as nontoxic (TRI-EPA), favoring the first and third principles. In addition, the atom economy is in the order of $71.43 \%$, a value considered as a good approach to the second principle.

Consequently, the best processes were developed employing $\mathrm{EtOH}$ as solvent, offering higher yields in comparison with solventless conditions. From these strategies, the MW and NIR irradiations are the best alternatives because they offer, in general, the same yields, but the microwaves' use in obtaining the title molecules is well known; however, NIR irradiation is offered as clean energy source to activate reactions, being easily controllable and with the quality of a fast responding heat source [33].
The structural identification of products $\mathbf{3 a}-\mathbf{e}$ was made on the basis of their corresponding spectral data. The compounds $\mathbf{3} \mathbf{a}, \mathbf{3 b}, \mathbf{3} \mathbf{d}$, and $\mathbf{3} \mathbf{e}$ were consistent with authentic ones in literature $[21,22]$. Since compound $3 c$ is a novel molecule, the corresponding spectroscopic data is discussed.

3.2. Spectroscopic Attribution. The ${ }^{1} \mathrm{H}$ NMR exhibited the expected singlet for the allylic proton $(\mathrm{H} 4)$ at $\delta 8.68$; also two double signals were assigned at $\delta 7.69(J=7.95 \mathrm{~Hz})$ and at $7.56(J=7.05 \mathrm{~Hz})$ to $\mathrm{H} 5$ and $\mathrm{H} 7$, respectively; a triplet at $\delta$ $7.26(J=7.65 \mathrm{~Hz})$ was assigned to H6; finally, the hydrogens of the methyl group (H9) were unequivocally assigned to a singlet at $\delta$ 2.34; the proton of $\mathrm{CO}_{2} \mathrm{H}$ was not observable, probably because the concentration of nuclei which produce the signal was poor or because of fast dissociation [36]; in addition, the exchange with the deuterated solvent or water from solvent itself can occur. The ${ }^{13} \mathrm{C}$ NMR spectrum contained four signals at $\delta 164.1,156.8,148.7$, and 125.1, which were appropriately assigned to $\mathrm{CO}_{2} \mathrm{H}, \mathrm{C} 2(\mathrm{C}=\mathrm{O}), \mathrm{C} 4$, and $\mathrm{C} 8$, respectively; the patterns for aryl and methyl groups were also observed in the experimental data, and these signals were corroborated by a HMBC experiment (three bonds distance): $\mathrm{H} 4$ correlated with $\mathrm{C} 8 \mathrm{a}$ at $\delta 152.8$, with $\mathrm{C} 5$ at $\delta$ 127.9, with $\mathrm{C} 2(\mathrm{C}=\mathrm{O})$ at $\delta 156.8$, and with $\mathrm{CO}_{2} \mathrm{H}$ at $\delta 164.1$. 
The hydrogen of the methyl group correlated with $\mathrm{C} 7$ at $\delta$ 135.3, and $\mathrm{H} 5$ correlated with C8a at $\delta 152.8$ and $\mathrm{C} 7$ at $\delta$ 135.3. In EIMS spectrum, the molecular ion at $m / z 204$ was observed, in addition to the base peak at $\mathrm{m} / z 160$ assigned to ion-fragment $[\mathrm{M}-44]^{+\bullet}$; some other worthy of note fragments are $m / z 187[\mathrm{M}-17]^{+}, m / z 132[\mathrm{M}-72]^{+\bullet}$, and $m / z$ $103[\mathrm{M}-101]^{+}$. Finally, the respective HRMS-DART ${ }^{+}$results were in agreement with the expected elemental composition, $\mathrm{C}_{11} \mathrm{H}_{9} \mathrm{O}_{4}$ : calculated $\mathrm{m} / z 205.0501$ and experimental $\mathrm{m} / z$ 205.0509 (3.80 ppm error) $[\mathrm{M}+\mathrm{H}]^{+}$.

\section{Conclusions}

In conclusion, coumarin-3-carboxylic acids $\mathbf{3 a}-\mathbf{e}$ have been prepared using a one-pot procedure, where the best synthetic strategy was obtained in solution conditions. Different activating energy sources were employed, providing several environmental benefits: less energy consumption, product isolation by simple filtration, and use of ethanol as a green solvent, without catalyst and very good atom economy. In other words, the overall process occurs with a good incidence in the Green Chemistry Protocol (the twelve principles). The NIR irradiation is proposed as a new alternative and as a clean energy to produce this kind of molecules.

\section{Competing Interests}

The authors declare no potential conflict of interests.

\section{Acknowledgments}

The authors appreciate the financial support to the Cátedra Química Verde-PIAPIC13, FESC-UNAM, and also CONACyT-México $\mathbf{2 0 5 2 8 9}$ for the postdoctoral scholarship to Joel Martínez.

\section{References}

[1] M. J. Matos, L. Santana, E. Uriarte, O. A. Abreu, E. Molina, and E. G. Yordi, "Coumarins-an important class of phytochemicals," in Phytochemicals-Isolation, Characterization and Role in Human Health, A. V. Rao and L. G. Rao, Eds., pp. 113-140, InTech, 2015.

[2] C. Kontogiorgis and D. Hadjipavlou-Litina, "Biological evaluation of several coumarin derivatives designed as possible antiinflammatory/antioxidant agents," Journal of Enzyme Inhibition and Medicinal Chemistry, vol. 18, no. 1, pp. 63-69, 2003.

[3] C. Spino, M. Dodier, and S. Sotheeswaran, "Anti-HIV coumarins from calophyllum seed oil," Bioorganic and Medicinal Chemistry Letters, vol. 8, no. 24, pp. 3475-3478, 1998.

[4] I. Kempen, D. Papapostolou, N. Thierry et al., "3-Bromophenyl 6-acetoxymethyl-2-oxo-2H-1-benzopyran-3-carboxylate inhibits cancer cell invasion in vitro and tumour growth in vivo," British Journal of Cancer, vol. 88, no. 7, pp. 1111-1118, 2003.

[5] S. Vilar, E. Quezada, L. Santana et al., "Design, synthesis, and vasorelaxant and platelet antiaggregatory activities of coumarin-resveratrol hybrids," Bioorganic and Medicinal Chemistry Letters, vol. 16, no. 2, pp. 257-261, 2006.
[6] E. Quezada, G. Delogu, C. Picciau et al., "Synthesis and vasorelaxant and platelet antiaggregatory activities of a new series of 6-Halo-3-phenylcoumarins," Molecules, vol. 15, no. 1, pp. 270-279, 2010.

[7] R. O. Kennedy and R. D. Thornes, Coumarins: Biology, Applications, and Mode of Action, John Wiley \& Sons, New York, NY, USA, 1997.

[8] H. von Pechmann, "Neue bildungsweise der cumarine. Synthese des daphnetins. I," Berichte der Deutschen Chemischen Gesellschaft, vol. 17, no. 1, pp. 929-936, 1884.

[9] J. R. Johnson, “The Perkin and related reactions," Organic Reactions, vol. 1, pp. 210-265, 1942.

[10] G. Brufola, F. Fringuelli, O. Piermatti, and F. Pizzo, "Simple and efficient one-pot preparation of 3-substituted coumarins in water," Heterocycles, vol. 43, no. 6, pp. 1257-1266, 1996.

[11] R. L. Shriner, “The Reformatsky reaction," Organic Reactions, vol. 1, pp. 1-37, 1942.

[12] I. Yavari, R. Hekmat-Shoar, and A. Zonouzi, "A new and efficient route to 4-carboxymethylcoumarins mediated by vinyltriphenylphosphonium salt," Tetrahedron Letters, vol. 39, no. 16, pp. 2391-2392, 1998.

[13] N. Cairns, L. M. Harwood, and D. P. Astles, “Tandem thermal Claisen-cope rearrangements of coumarate derivatives. Total syntheses of the naturally occurring coumarins: suberosin, demethylsuberosin, ostruthin, balsamiferone and gravelliferone," Journal of the Chemical Society, Perkin Transactions 1, no. 21, pp. 3101-3107, 1994.

[14] K. Pihlaja, M. Seilo, U. Svanholm, A. M. Duffield, A. T. Balaban, and J. C. Craig, "The acidity and general base-catalyzed hydrolysis of Meldrum's acid and its methyl derivatives," Acta Chemica Scandinavica, vol. 23, pp. 3003-3010, 1969.

[15] M. O. Noguez, V. Marcelino, H. Rodríguez et al., "Infrared assisted production of 3,4-dihydro-2(1H)-pyridones in solventfree conditions," International Journal of Molecular Sciences, vol. 12, no. 4, pp. 2641-2649, 2011.

[16] V. V. Lipson and N. Y. Gorobets, "One hundred years of Meldrum's acid: advances in the synthesis of pyridine and pyrimidine derivatives," Molecular Diversity, vol. 13, no. 4, pp. 399-419, 2009.

[17] A. S. Ivanov, "Meldrum's acid and related compounds in the synthesis of natural products and analogs," Chemical Society Reviews, vol. 37, no. 4, pp. 789-811, 2008.

[18] R. Maggi, F. Bigi, S. Carloni, A. Mazzacani, and G. Sartori, "Uncatalysed reactions in water-part 2. Preparation of 3carboxycoumarins," Green Chemistry, vol. 3, no. 4, pp. 173-174, 2001.

[19] B. P. Bandgar, L. S. Uppalla, and D. S. Kurule, "Solvent-free one-pot rapid synthesis of 3-carboxycoumarins: using focused microwaves," Green Chemistry, vol. 1, no. 5, pp. 243-245, 1999.

[20] B. Bandgar, L. Uppalla, and V. Sadavarte, "Lithium perchlorate and lithium bromide catalysed solvent free one pot rapid synthesis of 3-carboxycoumarins under microwave irradiation," Journal of Chemical Research, vol. 2002, no. 1, pp. 40-41, 2002.

[21] A. Song, X. Wang, and K. S. Lam, "A convenient synthesis of coumarin-3-carboxylic acids via Knoevenagel condensation of Meldrum's acid with ortho-hydroxyaryl aldehydes or ketones," Tetrahedron Letters, vol. 44, no. 9, pp. 1755-1758, 2003.

[22] F. Bigi, L. Chesini, R. Maggi, and G. Sartori, "Montmorillonite $\mathrm{KSF}$ as an inorganic, water stable, and reusable catalyst for the Knoevenagel synthesis of coumarin-3-carboxylic acids," The Journal of Organic Chemistry, vol. 64, no. 3, pp. 1033-1035, 1999. 
[23] E. A. Gunnewegh, A. J. Hoefnagel, R. S. Downing, and H. van Bekkum, "Environmentally friendly synthesis of coumarin derivatives employing heterogeneous catalysis," Recueil des Travaux Chimiques des Pays-Bas, vol. 115, no. 4, pp. 226-230, 1996.

[24] A. de la Hoz, A. Moreno, and E. Vázquez, "Use of microwave irradiation and solid acid catalysts in an enhanced and environmentally friendly synthesis of coumarin derivatives," Synlett, no. 5, pp. 608-610, 1999.

[25] J. L. Scott and C. L. Raston, "Solvent-free synthesis of 3carboxycoumarins," Green Chemistry, vol. 2, no. 5, pp. 245-247, 2000.

[26] B. T. Watson and G. E. Christiansen, "Solid phase synthesis of substituted coumarin-3-carboxylic acids via the Knoevenagel condensation," Tetrahedron Letters, vol. 39, no. 33, pp. 60876090, 1998.

[27] J. Ferguson, F. Zeng, and H. Alper, "Synthesis of coumarins via Pd-catalyzed oxidative cyclocarbonylation of 2-vinylphenols," Organic Letters, vol. 14, no. 21, pp. 5602-5605, 2012.

[28] L. C. C. Vieira, M. W. Paixâo, and A. G. Corrêa, "Green synthesis of novel chalcone and coumarin derivatives via Suzuki coupling reaction," Tetrahedron Letters, vol. 53, no. 22, pp. 2715-2718, 2012.

[29] N. G. Khaligh, "Ultrasound-assisted one-pot synthesis of substituted coumarins catalyzed by poly(4-vinylpyridinium) hydrogen sulfate as an efficient and reusable solid acid catalyst," Ultrasonics Sonochemistry, vol. 20, no. 4, pp. 1062-1068, 2013.

[30] G. Brahmachari, "Room temperature one-pot green synthesis of coumarin-3-carboxylic acids in water: a practical method for the large-scale synthesis," ACS Sustainable Chemistry and Engineering, vol. 3, no. 9, pp. 2350-2358, 2015.

[31] M. Morales, J. Martínez, L. Reyes-Sánchez et al., "How green an experiment is?" Educacion Quimica, vol. 22, no. 3, pp. 240-248, 2011.

[32] Toxics Release Inventory (TRI) Program, https://www.epa.gov/ toxics-release-inventory-tri-program/tri-listed-chemicals.

[33] R. Escobedo, R. Miranda, and J. Martínez, "Infrared irradiation: toward green chemistry, a review," International Journal of Molecular Sciences, vol. 17, no. 4, p. 453, 2016.

[34] G.-W. Wang, "Mechanochemical organic synthesis," Chemical Society Reviews, vol. 42, no. 18, pp. 7668-7700, 2013.

[35] A. N. Meldrum, "LIV.-a $\beta$-lactonic acid from acetone and malonic acid," Journal of the Chemical Society, Transactions, vol. 93, pp. 598-601, 1908.

[36] L. M. Jackman and S. Sternell, Applications of Nuclear Magnetic Resonance Spectroscopy in Organic Chemistry, Pergamon, Oxford, UK, 2nd edition, 1972.

[37] K. Nakayama and J.-M. Martin, "Tribochemical reactions at and in the vicinity of a sliding contact," Wear, vol. 261, no. 3-4, pp. 235-240, 2006.

[38] C. O. Kappe, "Controlled microwave heating in modern organic synthesis," Angewandte Chemie-International Edition, vol. 43, no. 46, pp. 6250-6284, 2004.

[39] B. Hayes, Microwave Synthesis: Chemistry at the Speed of Light, CEM Publishing, Matthews, NC, USA, 2002.

[40] M. Doxsee and E. Hutchison, Green Organic Chemistry Strategies, Tools, and Laboratory Experiments, Thomson Brooks/Cole, Minister, Ohio, USA, 1st edition, 2004. 

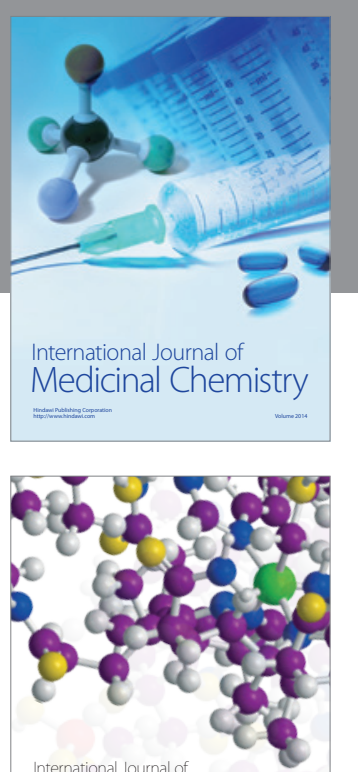

Carbohydrate Chemistry

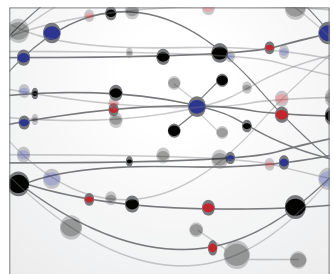

The Scientific World Journal
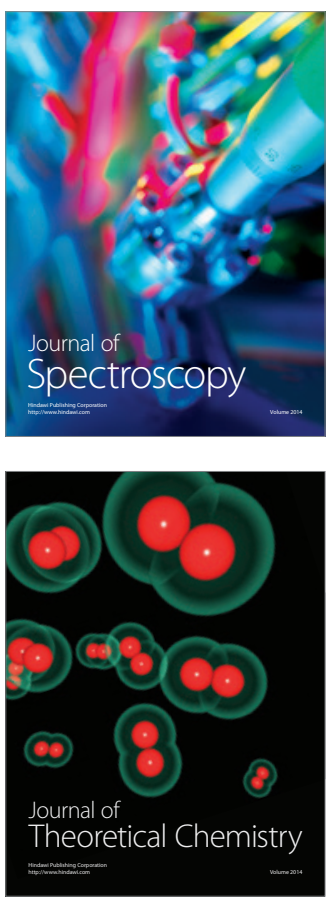
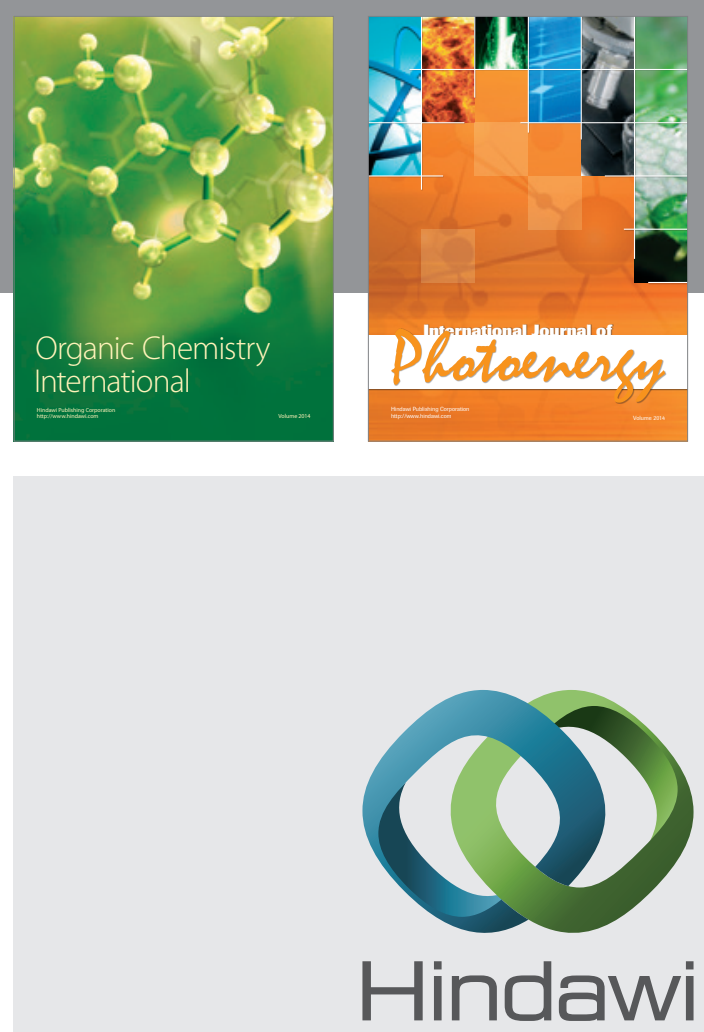

Submit your manuscripts at

http://www.hindawi.com

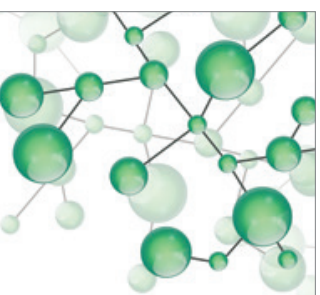

International Journal of

Inorganic Chemistry

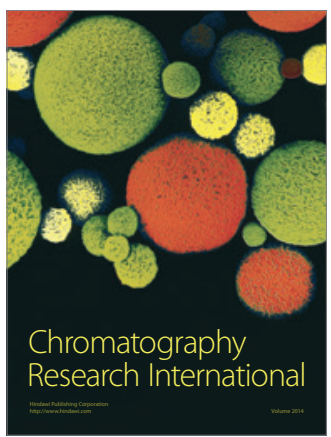

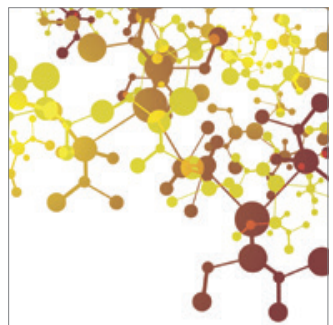

Applied Chemistry
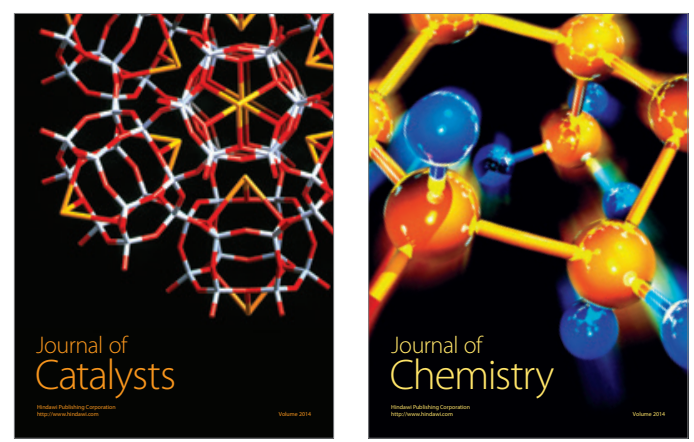
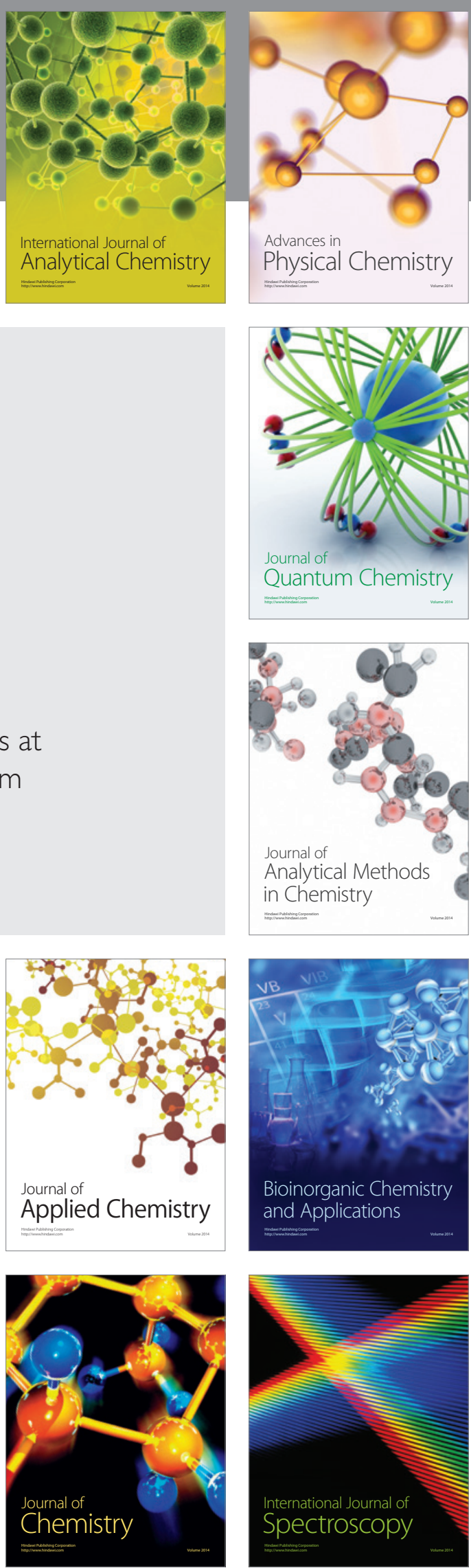